\title{
Wireless LAN PLANNING AND Performance ANALYSIS
}

\section{LePaja, S., ARianit Maraj, A. \& BerZati, S.}

Abstract: In the past, WLAN planning was coverage driven to ensure that the signal quality is satisfied in all targeted areas. As the number of users with more highthroughput applications, supported by sophisticated mobile computing devices, continues to grow rapidly on the one hand and on the other hand the new high-speed IEEE802.11 based WLANs continue to have a significant wireless communication market spread, it has been recognized that capacity is equally important as coverage for the WLAN planning. In this paper WLANs capacity planning and performance evaluation focusing on the impact of the applications throughput requirements, highspeed IEEE802.11 WLAN standards and user terminal capabilities are discussed. To investigate the impact of the high-speed WLANs and user terminal capabilities on the network throughput, performance evaluation is carried out by means of measurements, using IEEE 802.1 1ac and IEEE 802.11n standards.

Key words: Wireless Local Area Networks, WLAN planning, frequency bands, channel planning, user applications, user terminals capabilities
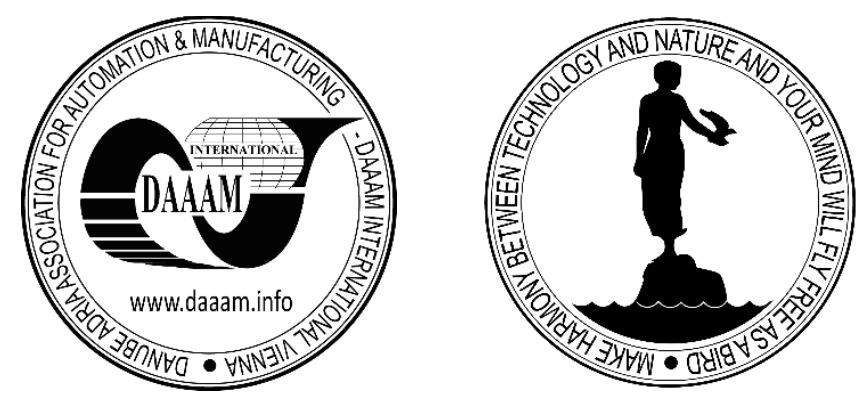

Authors' data: Lepaja, S[alem]; Maraj, A[rianit]; Berzati, S[hpat], AAB College, Faculty of Computer Sciences, Mat1-Banesat e Standardit, 10000 Prishtina, Kosovo, arianit.maraj@universitetiaab.com

This Publication has to be referred as: Lepaja, S[alem]; Maraj, A[rianit] \& Berzati, S[hpat] (2018). Wireless LAN Planning and Performance Analysis, Chapter 26 in DAAAM International Scientific Book 2018, pp.297-308, B. Katalinic (Ed.), Published by DAAAM International, ISBN 978-3-902734-19-8, ISSN 1726-9687, Vienna, Austria

DOI: $10.2507 /$ daaam.scibook.2018.26 


\section{Introduction}

Wireless Local Area Networks (WLANs) planning in the past, aimed to ensure that S/N (Signal to Noise and Interference ratio) and RSSI (Received Signal Strength Indicator) are satisfied in all covered areas. However, as the number of users with more bandwidth hungry applications, supported by sophisticated mobile computing devices such as smartphones, tablets, PDAs, laptops, continues to grow rapidly on the one hand and on the other hand high-speed IEEE802.11n and IEEE802.11ac based WLANs continue to mark a huge wireless communication market spread, it has been recognized that capacity is equally important as coverage for current and future WLAN planning. Hence, coverage and capacity planning must be done simultaneously in order to satisfy user requirements in terms of the data rate provisioning and the signal quality within the coverage area [1-4].

In this paper WLANs capacity planning and performance evaluation focusing on the impact of the applications throughput requirements, high-speed IEEE 802.11ac standard with $40 \mathrm{MHz}$ and $80 \mathrm{MHz}$ channels, IEEE $802.11 \mathrm{n}$ standard with $40 \mathrm{MHz}$ channel, and user terminal capabilities are presented.

The basic steps of the WLAN Planning are presented in the next section. In Section 3, we describe the channel planning in the $2.4 \mathrm{GHz}$ ISM (Industrial Scientific Medical) and in the 5GHz UNII (Unlicensed National Information Infrastructure) frequency bands. Calculation of the capacity planning, taking into consideration different user device capabilities and user applications throughput are given in Section 4. In Section 5 we present the measurement environment and the performance evaluation. Conclusions are drawn in the last section.

\section{Basic steps for WLAN Planning}

In general WLAN planning is carried out in several steps as shown in Figure 1. The starting step is the survey on WLAN communication requirements, which includes users and communication environment survey for the targeted area. The next step is the channel planning development. For channel planning we have to take into consideration available WLAN frequency bands and channels, IEEE802.11 standards, and communication environment. Having provided data for WLAN and channel planning, the next step is the WLAN dimensioning.

Dimensioning of the WLANs encounters determining the needed APs to ensure that capacity, S/N (Signal to Noise and Interference ratio) and RSSI (Received Signal Strength Indicator) are satisfied, taking into consideration applications throughput, number and type of user devices. In addition, the vendor's recommendation and planner's experience should be considered. In the network layout and optimization phase, the floor plan with APs location and assigned channels should be specified. 


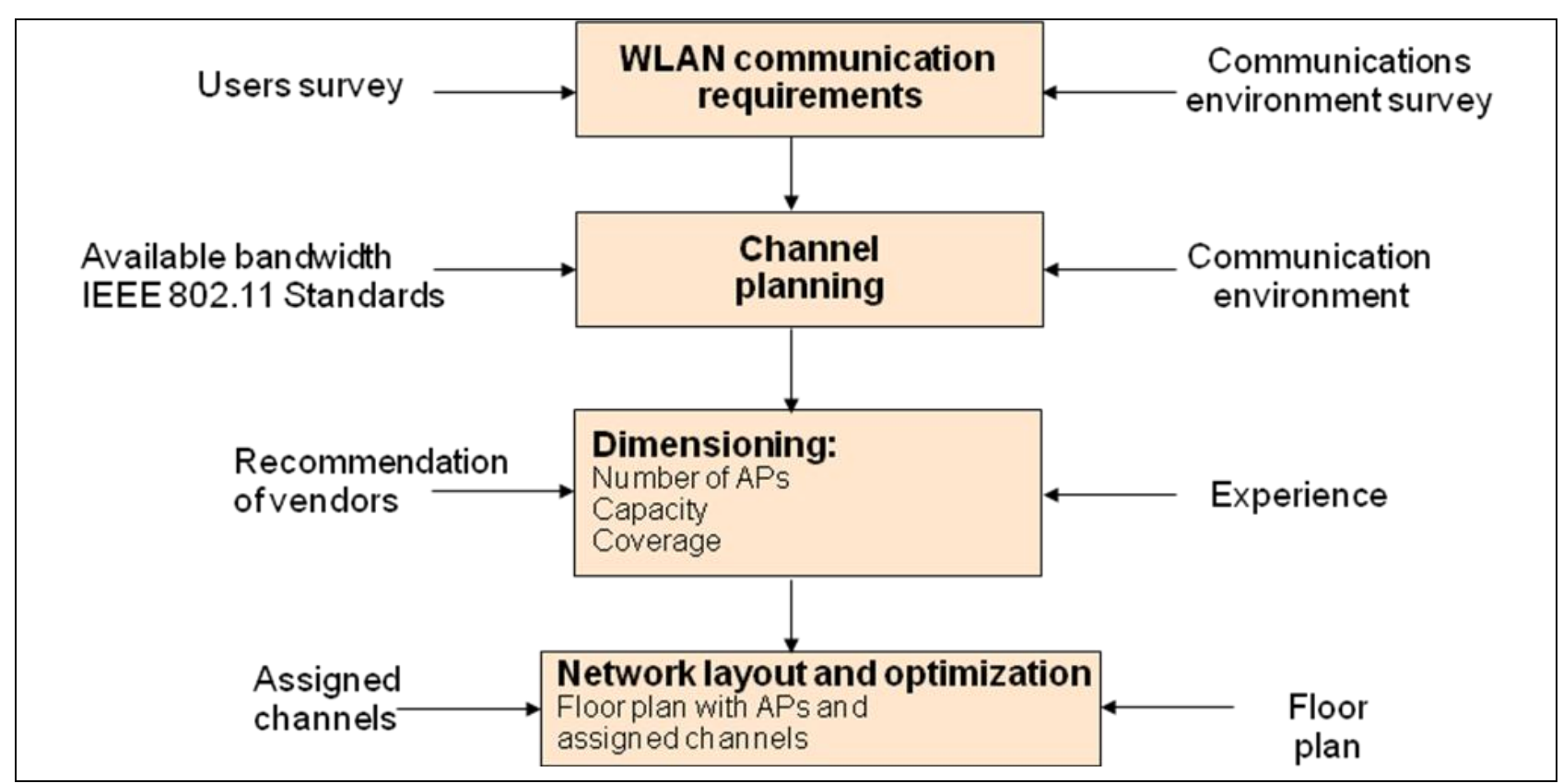

Fig. 1. Basic steps for WLAN planning

\section{a. User survey}

The user survey consists of collecting data such as: number of users and their category, user density in each targeted area, user device capabilities, type of the demanded applications as well as their throughput requirements.

\section{b. Communication environment survey}

In addition to the user survey, for successful WLAN planning, data about the size of the coverage area, type of the communication environment (closed, open, mobile), buildings architecture (one or more floors, offices spread out in two buildings) also are crucial. Furthermore, it is important to have some inputs about existing communication infrastructure (LAN network and connection to the Internet) in the covered area.

\section{Channel planning in $2.4 \mathrm{GHz}$ ISM and $5 \mathrm{GHz}$ UNII frequency bands}

In this section, we will explore the channel planning in the $2.4 \mathrm{GHz}$ and in the $5 \mathrm{GHz}$ band. In IEEE802.11 standards, there are defined fourteen channels in the $2.4 \mathrm{GHz}$ band, each $22 \mathrm{MHz}$. The availability of these channels is governed from local authorities of different Countries.

In Europe, there are 13 channels allowed for use, whereas in the United States 11 channels are allowed. Furthermore, in the $2.4 \mathrm{GHz}$ band, there are only three nonoverlapping channels 1, 6 and 11, as shown in Fig 2. It is clearly seen that most of the channels in the $2.4 \mathrm{GHz}$ band overlap.

Limited available bandwidth and channel overlapping results in the low number of the available channels in 2.4GHz. Hence, implementation of highspeed IEEE 802.11 standards in the $2.4 \mathrm{GHz}$ band is not suitable in high density areas [5]. 
Lepaja, S.; Maraj, A. \& Berzati, S.: Wireless LAN Planning and Performance Anal...

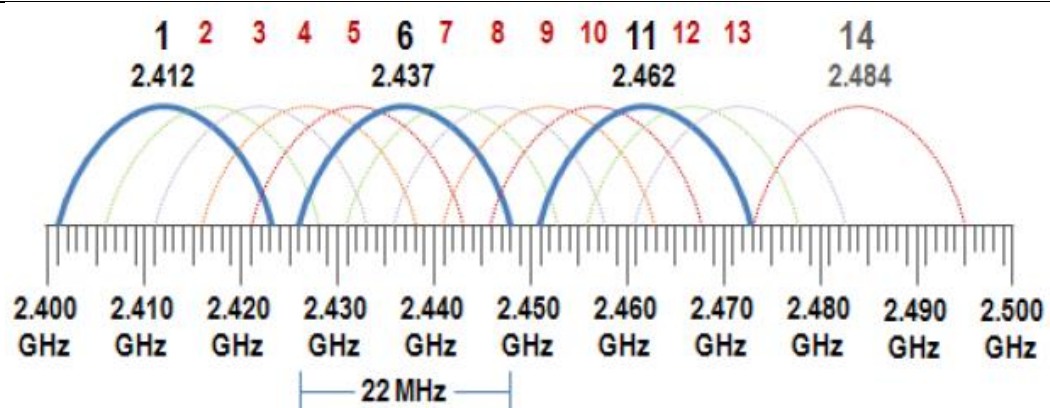

Fig. 2. WLAN channels in 2.4GHz band [5]

Different from $2.4 \mathrm{GHz}$ band, IEEE802.11 standard defines 23 channels in the $5 \mathrm{GHz}$ band, each 20MHz (Fig 3). As seen from the Fig 3, channels are spaced $20 \mathrm{MHz}$ apart and separated in three UNII bands.

The most critical issue in channel planning is interference avoidance. There are two types of channel interferences in WLAN environment: Co-Channel Contention (CCC) and adjacent channel interference. The CCC (also called co-channel interference) is when APs operate on the same frequency and interfere with each other. Actually, it is about contention between all users for a wireless channel on the same frequency (Carrier Sense Multiple Access with Collision Avoidance - CSMA/CA) and it is not like other RF (Radio Frequency) interference. CCI is a crucial factor for the capacity planning. Adjacent channel interference is when APs operate on the different channels and still interfere with each other. This type of interference is also an important factor to consider in WLAN planning.

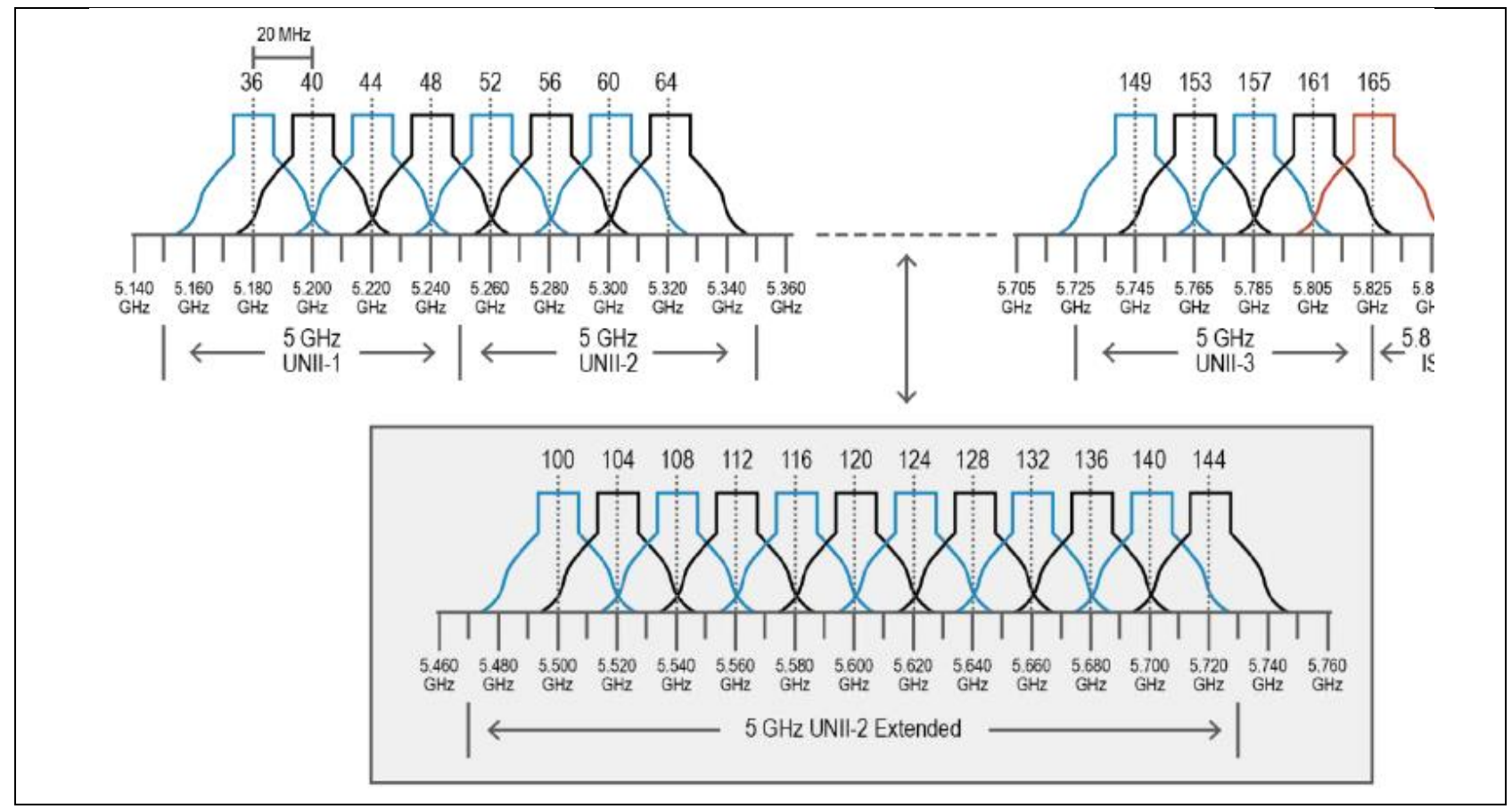

Fig. 3. WLAN channels in 5GHz band [5]

In capacity based WLAN planning, network administrators should design Wi-Fi cells (Fig 4) with associated range (adjacent channel interference) between $-65 \mathrm{dBm}$ to $67 \mathrm{dBm}$. 
At the same time they should develop a channel plan that ensures that CCC interference remains below $-85 \mathrm{dBm}$, considering the noise floor to be $<-85 \mathrm{dBm}$, whereas $\mathrm{S} / \mathrm{N}$ : 25 to $30 \mathrm{~dB}$. For coverage based planning received signal strength is usually $-72 \mathrm{dBm}$ [6].

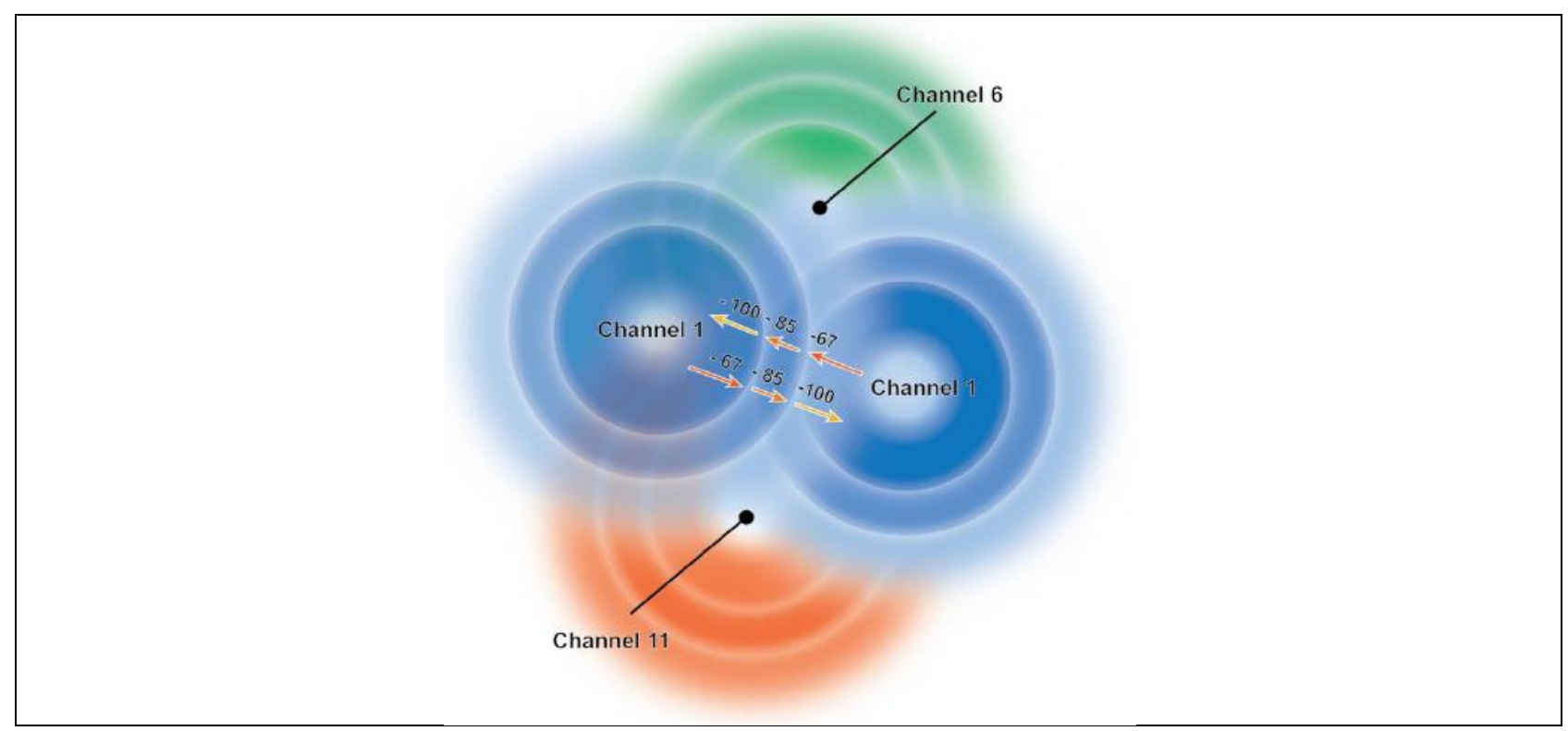

Fig. 4. Contention and association range [6]

\section{Capacity planning}

The WLAN planning in the past was mainly coverage driven to ensure that signal quality ( $\mathrm{S} / \mathrm{N}$ and RSSI) is satisfied in all targeted areas. However, as users demands for high-throughput applications supported by mobile computing devices such as smartphones, tablets, PDAs, laptops, continue to grow rapidly, it has been recognized that providing coverage does not mean enough capacity. Hence, capacity is equally important as coverage for the WLAN planning to meet the user requirements. Capacity planning in terms of the needed number of the APs is based on airtime utilization of the shared wireless link. By airtime utilization we understand the time an application occupies on wireless link, which depends on throughput of the application and on the user device capabilities. For example, a $2 \mathrm{Mbps}$ application generated by a laptop with $100 \mathrm{Mbps}$ capability needs $2 \%$ airtime utilization of the wireless channel. In the following paragraphs, we will present two examples to show how the airtime utilization is calculated i.e. number of needed APs for the given application throughput and the given device capability.

Example 1: We will assume that we have 50 Laptops with 2x2:2 MIMO, 144 Mbps raw data rate (Table 1), and TCP throughput of 70 Mbps. Whereas E-Learning applications with 2 Mbps throughput [6]. The airtime utilization is calculated as follows: $(2 / 70) \times 100=2.85 \%$, for a single laptop. For 50 laptops airtime utilization would be: $50 \times 2.85 \%=143 \%$. Furthermore, taking into consideration practical case of the AP channel saturation at $80 \%,(143 / 80)=1.8$, i.e. 2 APs are needed to satisfy capacity requirements. 
Lepaja, S.; Maraj, A. \& Berzati, S.: Wireless LAN Planning and Performance Anal...

\begin{tabular}{|c|c|c|c|c|c|c|c|}
\hline MCS & $\begin{array}{l}\text { Modulation } \\
\text { \& Rate }\end{array}$ & \begin{tabular}{|l}
20 \\
$\mathrm{MHz}$ \\
$1 \mathrm{x} \mathrm{S}$ \\
\end{tabular} & \begin{tabular}{|l}
20 \\
$\mathrm{MHz}$ \\
$2 \mathrm{x} \mathrm{S}$ \\
\end{tabular} & \begin{tabular}{|l}
40 \\
$\mathrm{MHz}$ \\
$1 \mathrm{x} \mathrm{S}$ \\
\end{tabular} & $\begin{array}{l}40 \\
\mathrm{MHz} \\
2 \mathrm{x} \mathrm{S} \\
\end{array}$ & \begin{tabular}{|l}
80 \\
$\mathrm{MHz}$ \\
$1 \mathrm{x} \mathrm{S}$ \\
\end{tabular} & \begin{tabular}{|l}
80 \\
MHz \\
$2 \mathrm{x} \mathrm{S}$ \\
\end{tabular} \\
\hline 0 & BPSK $1 / 2$ & 7.2 & 14.4 & 15 & 30 & 32.5 & 65 \\
\hline 1 & QPSK 1/2 & 14.4 & 28.9 & 30 & 60 & 65 & 130 \\
\hline 2 & QPSK 3/4 & 21.7 & 43.3 & 45 & 90 & 97.5 & 195 \\
\hline 3 & 16-QAM 1/2 & 28.9 & 57.8 & 60 & 120 & 130 & 260 \\
\hline 4 & 16-QAM 3/4 & 43.3 & 86.7 & 90 & 180 & 195 & 390 \\
\hline 5 & 64-QAM 2/3 & 57.8 & 115.6 & 120 & 240 & 260 & 520 \\
\hline 6 & 64-QAM 3/4 & 65 & 130 & 135 & 270 & 292.5 & 585 \\
\hline 7 & 64-QAM 5/6 & 72.2 & 144.4 & 150 & 300 & 325 & 650 \\
\hline 8 & 256 QAM 3/4 & 86.7 & 173.3 & 180 & 360 & 390 & 780 \\
\hline 9 & 256-QAM 5/6 & F & t & 200 & 400 & 433.3 & 866.7 \\
\hline
\end{tabular}

Tab. 1. Selected Raw data rates in Mbps for IEEE802.11 standards [7, 8]

Example 2: This example is an extension of the example 1 with 30 more tablets $1 \times 1: 1$, with $65 \mathrm{Mbps}$ raw data rate (Table 1), and 30Mbps TCP throughput. Airtime utilization for added tablets would be: $(2 / 30) \times 100=6.66 \%$ for one tablet, whereas for 30 tablets, $30 \times 6.66 \%=200 \%$. In total airtime utilization will be $343 \%$. Assuming again practical case of the AP channel saturation at $80 \%$, we will come up with $(343 / 80)=4.3$, i.e. 5 APs needed to satisfy capacity requirements.

Based on the above examples, Fig 5 illustrates the impact of the applications throughput and the user devices capabilities on the number of the needed APs. Note the difference between raw data rate and TCP throughput due to WLAN overhead, which is usually between $40-60 \%$.

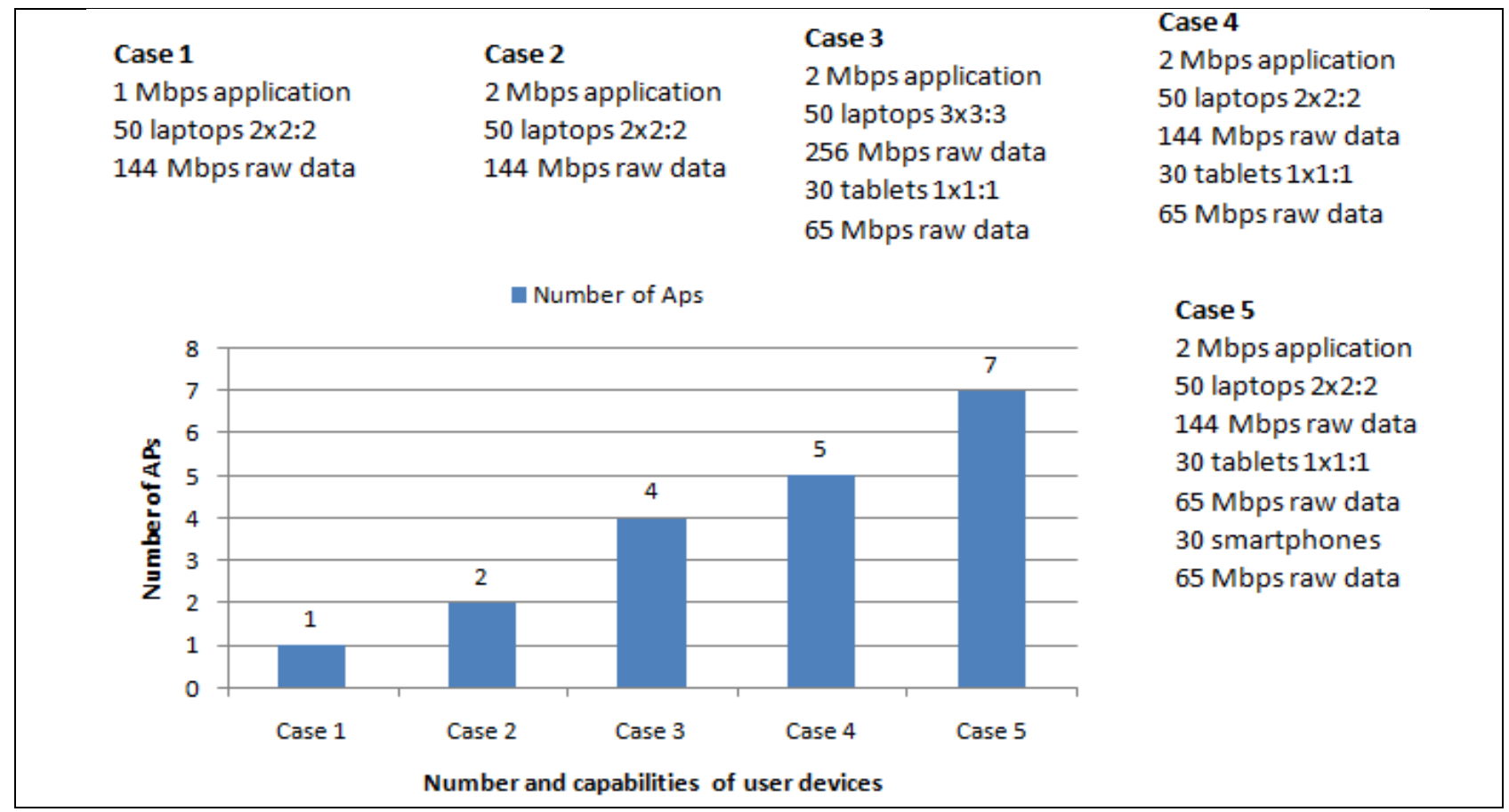

Fig. 5. Number of needed APs [7] 
From Fig 5 it can be seen that:

- applications with higher throughput require more APs (case 1,2)

- devices with better capabilities need less APs (case 3,4)

- increasing the number of the different devices more APs are needed (case 4,5)

\section{Measurement environment and performance evaluation}

To investigate the impact of the high-speed WLANs and user terminal capabilities on the network throughput, we have carried out thoroughly measurements using sophisticated tools. We considered only TCP throughput on Uplink.

\section{A. Measurement environment}

- Software tools: iperf 3, inSSIder, Aruba OS 6.4

- Devices

\begin{tabular}{|c|c|c|c|}
\hline - User Device Type & $\begin{array}{l}\text { - WiFi } \\
\text { Type }\end{array}$ & $\begin{array}{ll}\text { - } & \text { MIM } \\
& \mathrm{O} \\
\end{array}$ & $\begin{array}{l}\text { - Channel } \\
\text { Width } \\
\end{array}$ \\
\hline - iPhone 7 & $\begin{array}{l}\text { - } 802.11 \mathrm{a} / \mathrm{b} / \mathrm{g} / \mathrm{n} / \\
\mathrm{ac}\end{array}$ & - $2 \times 2$ & $\begin{array}{ll}\text { - } & 40 \mathrm{MHz} / 80 \mathrm{M} \\
& \mathrm{Hz}\end{array}$ \\
\hline - Samsung S7 & $\begin{array}{l}\text { - } 802.11 \mathrm{a} / \mathrm{b} / \mathrm{g} / \mathrm{n} / \\
\mathrm{ac}\end{array}$ & - $2 \times 2$ & $\begin{array}{l}\text { - } 40 \mathrm{MHz} / 80 \mathrm{M} \\
\mathrm{Hz}\end{array}$ \\
\hline - Xiaomi Note 3 & $\begin{array}{l}\text { - } 802.11 \mathrm{a} / \mathrm{b} / \mathrm{g} / \mathrm{n} / \\
\text { ac }\end{array}$ & - $1 \times 1$ & $\begin{array}{ll}\text { - } & 40 \mathrm{MHz} / 80 \mathrm{M} \\
& \mathrm{Hz}\end{array}$ \\
\hline 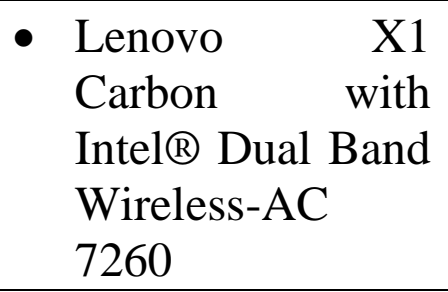 & $\begin{array}{l}\text { - } 802.11 \mathrm{a} / \mathrm{b} / \mathrm{g} / \mathrm{n} / \\
\mathrm{ac}\end{array}$ & - $2 \times 2$ & $\begin{array}{l}\text { - } 40 \mathrm{MHz} / 80 \mathrm{M} \\
\mathrm{Hz}\end{array}$ \\
\hline 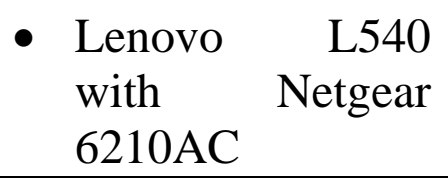 & $\begin{array}{l}\text { - } 802.11 \mathrm{a} / \mathrm{b} / \mathrm{g} / \mathrm{n} / \\
\mathrm{ac}\end{array}$ & - $2 \times 2$ & $\begin{array}{l}\text { - } 40 \mathrm{MHz} / 80 \mathrm{M} \\
\mathrm{Hz}\end{array}$ \\
\hline - Sony xPeria & $\begin{array}{l}\text { - } 802.11 \mathrm{a} / \mathrm{b} / \mathrm{g} / \mathrm{n} / \\
\mathrm{ac}\end{array}$ & - $1 \times 1$ & $\begin{array}{ll}\text { - } & 40 \mathrm{MHz} / 80 \mathrm{M} \\
& \mathrm{Hz} \\
\end{array}$ \\
\hline $\begin{array}{l}\text { - Lenovo Ideapad, } \\
\text { Intel Dual Band } \\
\text { Wireless- } \\
\text { AC(1x1) } 3165 \\
\end{array}$ & $\begin{array}{l}\text { - } 802.11 \mathrm{a} / \mathrm{b} / \mathrm{g} / \mathrm{n} / \\
\mathrm{ac}\end{array}$ & - $1 \mathrm{x} 1$ & $\begin{array}{l}\text { - } 40 \mathrm{MHz} / 80 \mathrm{M} \\
\mathrm{Hz}\end{array}$ \\
\hline \multicolumn{4}{|l|}{ - Server Device type } \\
\hline - HP Probook 4530 & $\triangle \mathrm{N} C$ & & \\
\hline
\end{tabular}

Tab. 2. User devices capabilities 
Lepaja, S.; Maraj, A. \& Berzati, S.: Wireless LAN Planning and Performance Anal...

- Network Infrastructure

To model a real WLAN environment is not an easy task because of different IEEE802.11 WLAN types and user devices encountered. For our goal of the investigation, we have set up a possible network model with one AP and several different user devices, as shown in Fig 6.

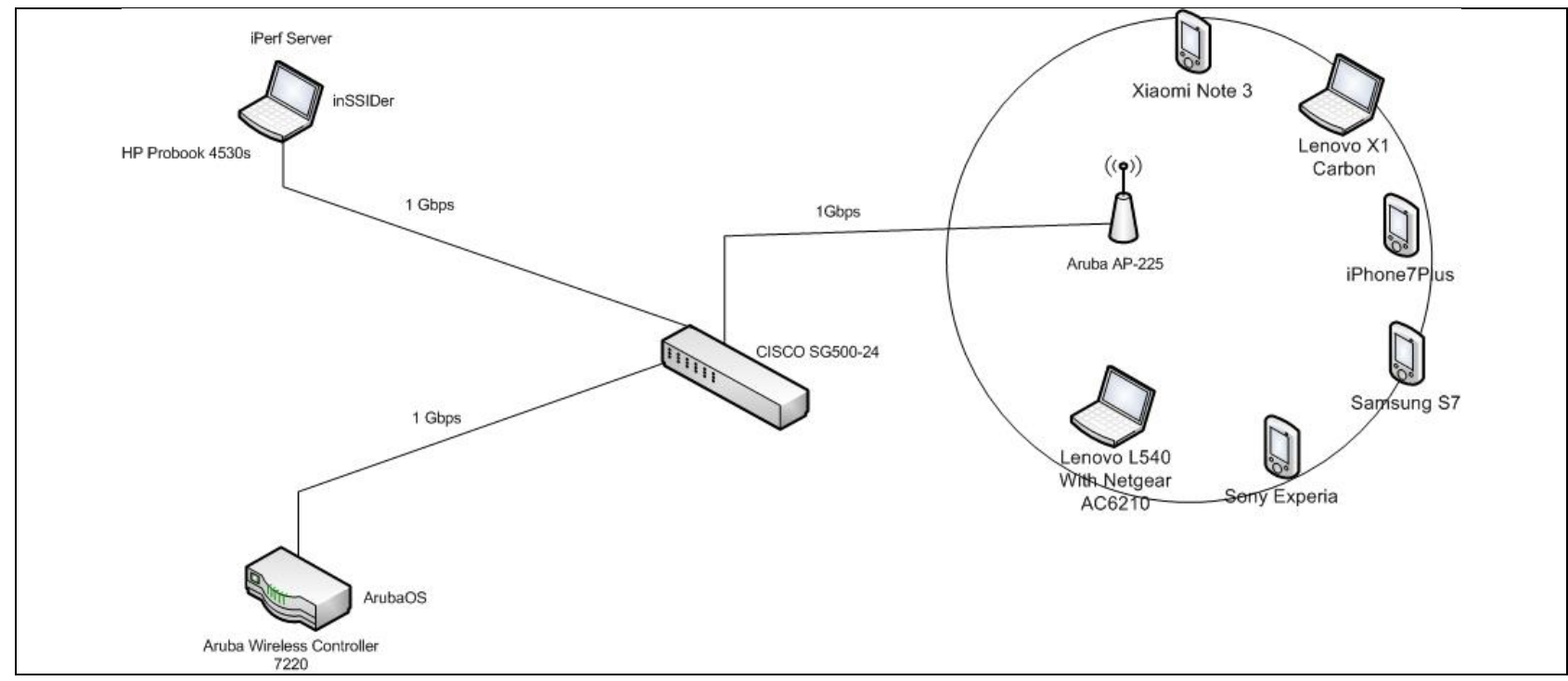

Fig. 6. Network infrastructure

\section{B. Performance evaluation}

\section{Case 1}

Throughput with one client device in the Dual-Band $(2.4 \mathrm{GHz} \& 5 \mathrm{GHz})$ and SingleBand $(5 \mathrm{GHz})$ mode with $40 \mathrm{MHz}$ channel width.

Used devices:

- Server: HP Probook 4530s with Gigabit LAN Card

- Client: iPhone 7 Plus, Samsung Galaxy S7, Lenovo L540 with Netgear 6210AC adapter

- WiFi AP Mode: Aruba AP-225 n

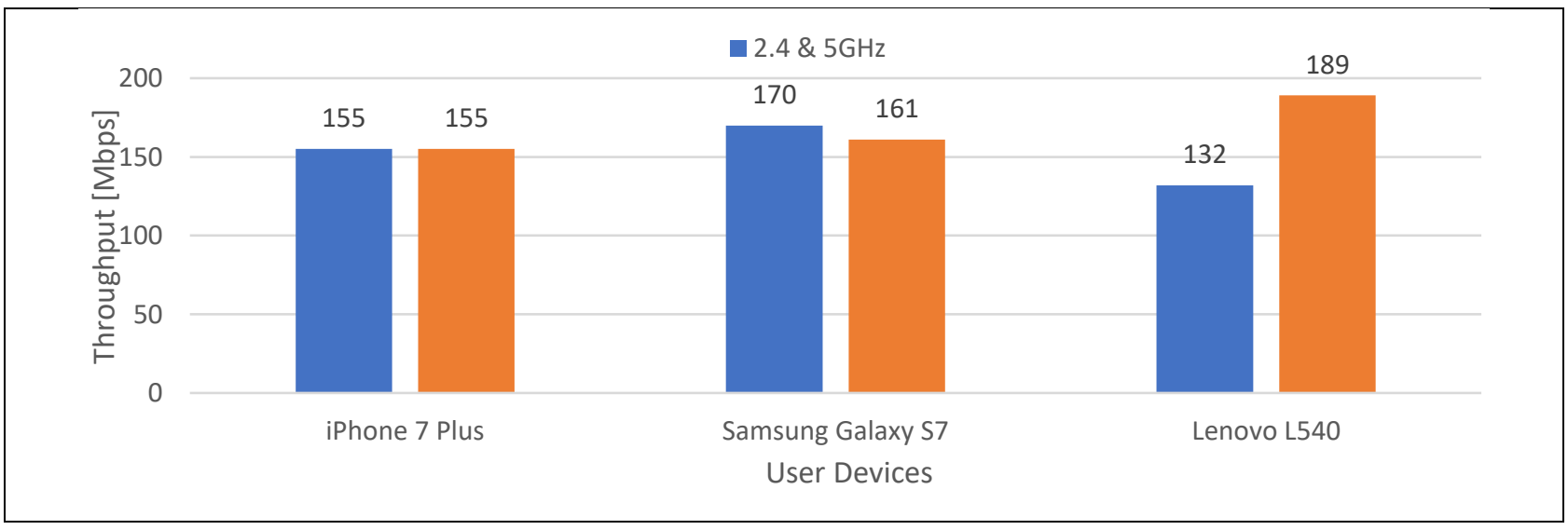

Fig. 7. Throughput with one client device 
As it can be seen from Fig 7, dual-band mode operation of the AP has no impact on performances, in terms of the network throughput, of the user devices operating only in the $5 \mathrm{GHz}$ band. Whereas, Lenovo L540 with Netgear 6210AC adapter performs better (results in higher network throughput), when operating in the $5 \mathrm{GHz}$ band compared to $2.4 \mathrm{GHz}$ band. This outcome is due to the higher channel overlapping and Co-Channel Contention interference in the $2.4 \mathrm{GHz}$ band.

\section{Case 2}

Throughput with one client device with default and 1Mbyte window size. Used devices:

- Server: HP Probook 4530s with Gigabit LAN Card

- Clients: iPhone 7 Plus \& Samsung Galaxy S7

- WiFi AP Mode: Aruba AP-225 n/ac

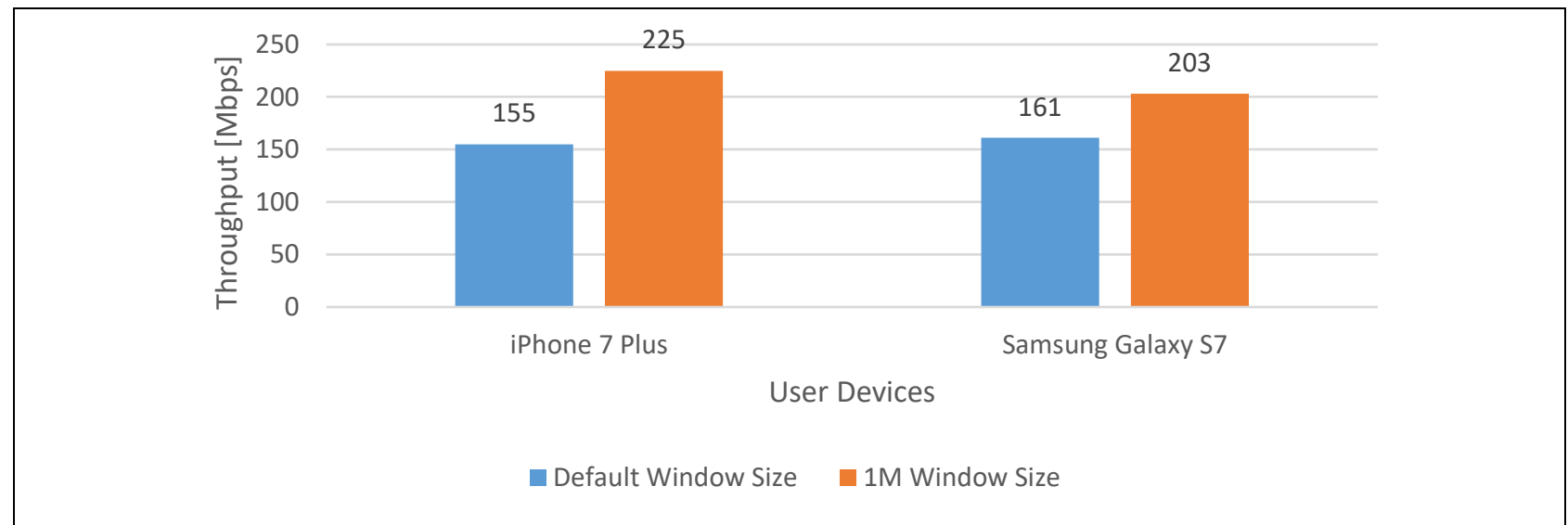

Fig. 8. Throughput with one client device with default and 1M Window Size

\section{Case 3}

Throughput for individual and combined devices with $40 \mathrm{MHz}$ channel width. Used devices:

- Server: HP Probook 4530s with Gigabit LAN Card

- Clients: iPhone 7 Plus, Samsung Galaxy S7 and Lenovo X1 Carbon with Intel® Dual Band Wireless-AC 7260

- WiFi AP Mode: Aruba AP-225 n/ac

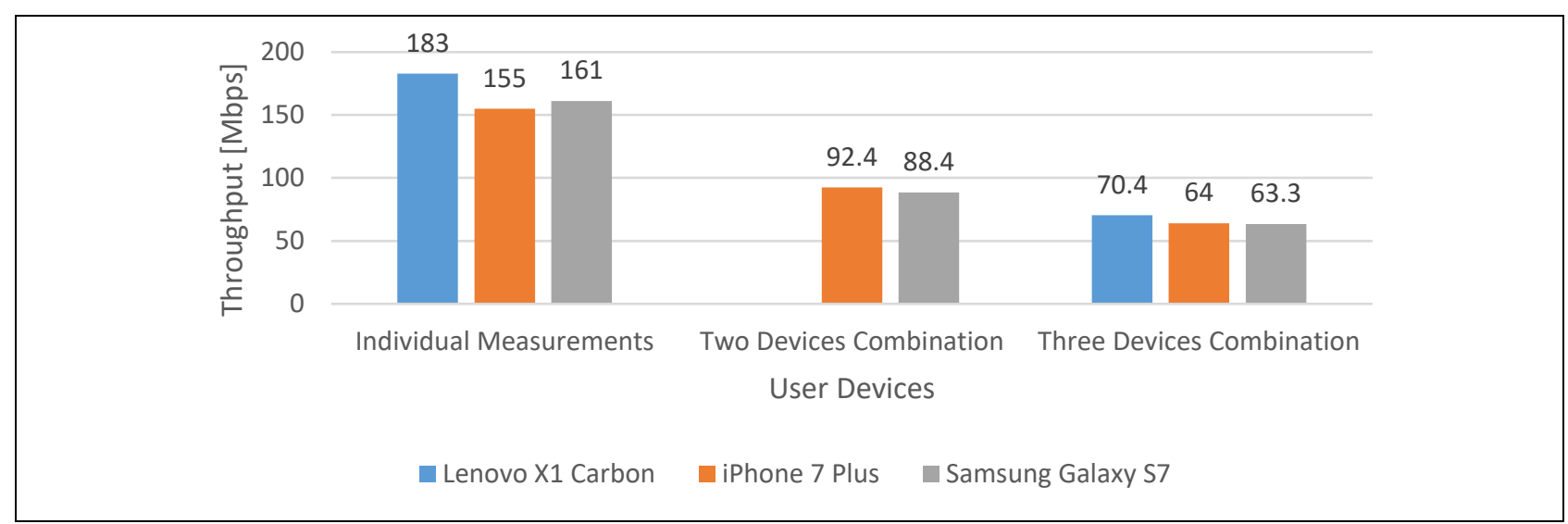

Fig. 9. Throughput for individual and combined devices with $40 \mathrm{MHz}$ channel width 
From the measurement results shown in Fig 9, we notice that the overall throughput with two clients $(180,8 \mathrm{Mbps})$ is higher than in the case of the single client (155Mbps, $158 \mathrm{Mbps})$, the overall throughput with three clients $(197,7 \mathrm{Mbps})$ is higher than the overall throughput with two clients. An explanation is that in the high-bandwidth, highlatency environments (bandwidth delay product), TCP communications are often limited by the amount of data on the way at any given time. Using two or more user devices simultaneously, i.e. two or more TCP connections in our case, overall link (network) throughput is increased because the bandwidth delay product applies to each user device connection individually.

\section{Case 4}

Throughput for individual and combined devices with $40 \mathrm{MHz}$ and $80 \mathrm{MHz}$ channel width.

Used devices:

- Server: HP Probook 4530s with Gigabit LAN Card

- Clients: iPhone 7 Plus and Samsung Galaxy S7

- WiFi AP Mode: Aruba AP-225 n/ac

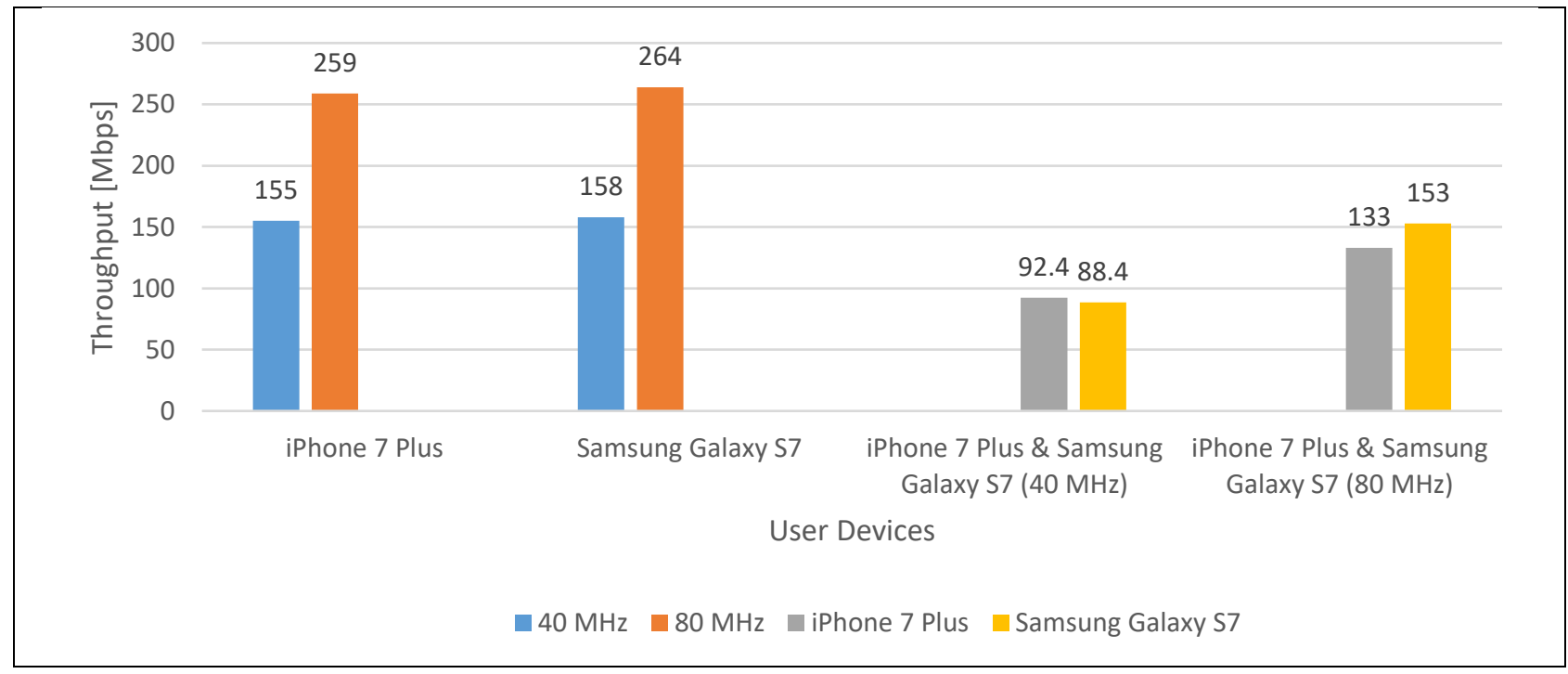

Fig. 10. Throughput for individual and combined devices with $40 \mathrm{MHz}$ and $80 \mathrm{MHz}$ channels

Fig 10 shows that operating with wider channels throughput increases significantly. However, doubling channel width does not lead to a doubling of throughput as it applies for raw data rate. Comparing raw data rates of $40 \mathrm{MHz}$ with $80 \mathrm{MHz}$ channels (Table 1), we notice that for devices with the same capabilities, the raw data rate of $80 \mathrm{MHz}$ channels is twice higher than with $40 \mathrm{MHz}$ channels [9]. Whereas, TCP throughput, in the case of using higher modulation such as the 256-QAM (used in IEEE802.11ac with $80 \mathrm{MHz}$ channel), increases by $33 \%$ [10]. 
From our measurement results, shown in Fig 10, it is noticeable a slightly throughput increase compared to the $33 \%$ in [10]. In the case of the single device measurements, the throughput results are nearly $40 \%$ higher with $80 \mathrm{MHz}$ channel compared to $40 \mathrm{MHz}$ channel. Whereas, in the case of the two devices sharing the wireless link we have about $36 \%$ throughput increase with $80 \mathrm{MHz}$ channel compared to $40 \mathrm{MHz}$ channel.

\section{Conclusion}

We have investigated WLAN capacity planning and performances evaluation focusing on the impact of the applications throughput requirements, high-speed IEEE802.11 standards, and user terminal capabilities. In the past WLAN planning was mainly coverage driven, ensuring that $\mathrm{S} / \mathrm{N}$ ratio and RSSI are satisfied in all covered area. Today with the massive increase of the wideband applications and high capability user devices, capacity is a crucial issue in WLAN planning to meet users' requirements. For WLAN planning driven by capacity, airtime utilization of the shared wireless link is the main parameter in determining the needed number of the APs. Presented calculations show that applications with higher throughput require more APs, whereas devices with better capabilities need less APs (Figure 5).

Measurement results show that dual-band mode operation of the AP has no impact on performances, in terms of network throughput, of the user devices operating only in the $5 \mathrm{GHz}$ band. Whereas, devices that can operate in both modes perform better in the $5 \mathrm{GHz}$ band (Fig 7). Furthermore, the TCP window size of 1Mbyte results in higher throughput compared to default window size of 64Kbytes (Fig 8), because the default window size is obviously too small to make full use of the end-to-end link capacity. Measurements also show (Fig 9) that the overall throughput with two client devices is higher than with a single client device, overall throughput with three clients is higher than overall throughput with two clients. An explanation is that in the highbandwidth links TCP communications are often limited by the amount of data on the way.

Using two or more user devices simultaneously i.e. two or more TCP connections, overall wireless link throughput is increased because the bandwidth delay product applies to each user device connection individually. Operating with wider channels, throughput increases significantly. However, doubling channel width does not lead to a doubling of throughput as it applies for raw data rate. From our measurement results (Fig 10), it is noticeable a slightly throughput increase compared to the $33 \%$ in [10]. In the case of the single device measurements, the throughput results are nearly $40 \%$ higher with $80 \mathrm{MHz}$ channel compared to $40 \mathrm{MHz}$ channel. Whereas, in the case of the two devices sharing the wireless link we have about $36 \%$ throughput increase with $80 \mathrm{MHz}$ channel compared to $40 \mathrm{MHz}$ channel. 
Lepaja, S.; Maraj, A. \& Berzati, S.: Wireless LAN Planning and Performance Anal...

\section{References}

Vanhatupa, Timo. "Wi-Fi Capacity Analysis for 802.11 ac and 802.11 n: Theory \& Practice." Ekahau Inc (2013).

S. Nitin Kelkar, "A survey and performance analysis of IEEE 802.11ac WiFi networking", ISSN 2348-1196 (print) International Journal of Computer Science and Information Technology Research ISSN 2348-120X (online) Vol. 3, Issue 2, pp: (808814), Month: April - June 2015

N. S. Ravindranath, Inder Singh, Ajay Prasad and V. S. Rao, Performance Evaluation of IEEE 802.11 ac and 802.11n using NS3, Indian Journal of Science and Technology, Vol 9(26), DOI: 10.17485/ijst/2016/v9i26/93565, July 2016, ISSN (Print) : 0974-6846, ISSN (Online) : 0974-5645

D. Maraj, R. Sefa and A. Maraj, "QoS Evaluation for different WLAN standards," 2015 23rd International Conference on Software, Telecommunications and Computer Networks (SoftCOM), Split, 2015, pp. 190-194. doi: 10.1109/SOFTCOM.2015.7314115

WiFi Basics and Best practices - Channel Planning Best Practices", Article ID: 2012, CISCO

High-Density Wi-Fi Design Principles, white paper, Copyright, 2012, Aerohive Networks, Inc.

S. Lepaja, "Wireless Local Area Networks Planning", IX Annual International Meeting of Alb_Science Institute, August 2014, Prishtina, Kosovo

Aruba 802.11ac Networks, Validated Reference Design, Copyright Information, () 2015 Aruba Networks

Matthew S. Gast, 802.11ac: A Survival Guide - Wi-Fi at Gigabit and Beyond”, By Publisher: O'Reilly Media, Final Release Date: July 2013, Pages: 154

[10] Christian J. Estes, "Evolutions in 802.11 Design High-Density, Capacity Planning and Survey Methodologies" 2015. 